\title{
Ontology model for intake suggestion and preparation for Malay confinement dietary recipes
}

\author{
M. Hamiz ${ }^{1}$, Haryani Haron ${ }^{2}$, M. Bakri ${ }^{3}$, Nur Liyana Mohd Lazim ${ }^{4}$ \\ ${ }^{1,3,4}$ Faculty of Computer and Mathematical Sciences, Universiti Teknologi MARA Cawangan Melaka Kampus Jasin, \\ Malaysia \\ ${ }^{2}$ Faculty of Computer and Mathematical Sciences, Universiti Teknologi MARA Cawangan Selangor Kampus Shah Alam, \\ Malaysia
}

\begin{tabular}{|c|c|}
\hline Article Info & ABSTRACT \\
\hline Article history: & \multirow{10}{*}{$\begin{array}{l}\text { This paper presents the ontology model for Malay Confinement Dietary } \\
\text { (MCD) recipes which include the intake suggestion and its preparation. MCD } \\
\text { plays a big role to ensure that mothers in confinement get the right nutrient in } \\
\text { order to restore back their health. In the current research on MCD, the } \\
\text { covered part is only on what are the foods allowed to be taken by mothers } \\
\text { during confinement and the nutrients that it can boost in mothers' body. } \\
\text { However, it does not include what are the preparation methods of the food } \\
\text { and what is the suggested intake time for that dish. These two aspects could } \\
\text { give the certainty factor for mothers to get the sufficient nutrient during } \\
\text { confinement. But those knowledges are known by the traditional Malay } \\
\text { midwives. Hence, this tacit knowledge should be modeled into an ontology } \\
\text { model as one of the knowledge preservation methods. Three new classes } \\
\text { together with four new object properties were added to the current model and } \\
\text { based on testing that has been done, the extended new model of ontology } \\
\text { could retrieve the correct information as needed. }\end{array}$} \\
\hline Received Mar 2, 2019 & \\
\hline Revised Jun 30, 2019 & \\
\hline Accepted Jul 29, 2019 & \\
\hline Keywords: & \\
\hline Confinement & \\
\hline Dietary & \\
\hline Model & \\
\hline Ontology & \\
\hline Recipe & \\
\hline
\end{tabular}

Copyright (c) 2020 Institute of Advanced Engineering and Science. All rights reserved.

\section{Corresponding Author:}

\section{Hamiz,}

Faculty of Computer and Mathematical Sciences,

Universiti Teknologi MARA Cawangan Melaka Kampus Jasin,

77000, Merlimau, Malaysia.

Email: hamizradzi@tmsk.uitm.edu.my

\section{INTRODUCTION}

A proper diet during confinement has become the tradition for Malay society in Malaysia. Since generations, the mothers in confinement believed that having a strict and suitable diet will make them healthier after giving birth. It is supported by [1] which stated that during the confinement period, consumption of certain foods helps in improving or recovering health, while other foods are restricted as they might cause illness either immediately or in the future. A balanced amount of nutrients in food is need for all human being regarding to proper body system functions [2]. Previously, no integrated information can be found regarding the suitable diet for Malay mothers in confinement period. Hence, an ontology model of Malay indigenous health knowledge which include Malay confinement dietary (MCD) information has been constructed to preserve the knowledge from extinction [3]. Another extension of the ontology model has been created to include the phytochemicals benefits to the allowed food in MCD which added the scientific reasons why the diet can be good to mothers in confinement's health [4]. Currently, in the latest ontology model for MCD, the information that can be fetched is only on what are the allowed or non-allowed foods, which nutrient does the food could enhance and the phytochemical benefits in the allowed fruits and vegetables. It does not cover on how the allowed foods should be prepared and when is the right time to take those foods. Since the food needs to be prepared as a dish for mothers in confinement, the MCD ontology 
model could be enhanced with the recipes on how to prepare the suitable dish with the right intake time for the mothers [5].

The intake of a confinement dish contributes in the absorption of nutrients into the body. The intake in this research consists of the time for a food to be consumed for a mother in confinement to get the correct nutrient. According to [5], the conventional intake of men and women is the three-meal pattern which is the breakfast, lunch and dinner. The authors added that women who follows the conventional three-meal pattern has higher energy and nutrient intake for their body. Usually, the midwives will provide the recipes for mothers which is a combination of the allowed foods for better health and faster wound healing. A study by [6] claimed that the recipes provided are for mothers in confinement to consume are tasty Malay dishes which can help in healing their body along with having a healthy diet. It is supported by [7] which stated that the recipes are great for mothers to have enough nutrient intake. Currently, few intake knowledges were found in the literature, but it is not enough as most of the knowledge on the intake can only be fetched from midwives' experience [8]. This midwives' experience is in a form of tacit knowledge. According to [9], tacit knowledge is coming from one's experience and it is highly personal and very context-specific. Hence, to preserve the tacit knowledge from the midwives, this paper presents an ontology model which could be a solution to model the knowledge so that it can be retrieved in the future.

\section{LITERATURE REVIEW}

The concept of ontology model is a part of knowledge management technology. When it comes to knowledge management, it is the process that integrates the tacit and explicit knowledge. Explicit knowledge implies the means of collecting the knowledge management methodologies, while on the other hand, tacit knowledge implies the means of connecting knowledge management methodology [10]. Usually, tacit knowledge is often possessed by some individuals in particular business environment [11]. One of the vital characteristics of knowledge management is representing knowledge in documents, databases and software. For the sake of representing knowledge, there are several stages that knowledge engineers need to know. First is the acquisition of knowledge where knowledge is in tacit form, scattered and unorganized. The knowledge specialist should learn and comprehend about the explicit and tacit detail of the knowledge and afterward utilize models and diagrams to illustrate the new knowledge as a communication among users and knowledge experts. After several discussions, a conceptual model will be developed based on the decisions which is the modelling of knowledge which one of it is an ontology model.

According to [12], the word ontology consists of two different perspectives which are the application of ontology to computer science and the philosophical roots perspectives. In the perspective of the philosophical roots, philosophers are keener in the philosophical ideas. Meanwhile, in the perspective of its application to computer science, ontology engineers focus on how ontologies are used to visualize, use and expand pieces of domain knowledge and methods of the ontology being applied in application. Therefore, ontology can be defined as the pieces of domain knowledge which will be constructed in a machine interpretable language [13, 14]. In addition, [15] suggested the two aims of ontologies are to explain the most commonly used terms in a specific domain which leads to constructing a skeleton and to allow the dissemination of knowledge. It is supported by [16] that ontology model helps to specify knowledge content.

According to [17], the components of ontology are Classes, Individuals and Relations. Classes which are also known as the types, concepts or universals are one of the main components of ontology. A class serves as a group of various Individuals which has common attributes. One class can be a subclass to another class and classes can also share relationships with one another. Meanwhile, Individuals or also called as instances or particulars, serve as the base unit of an ontology which are the things that an ontology describes and can be concrete objects (i.e.: people) or abstract object (i.e.: a person's job). The last component which is the relation is the way an ontology describes associations between Individuals or associations between Classes.

There are lots of ontology model examples that are focusing on the traditional knowledge such as MCD ontology model by [3, 4, 5] and Indonesia Jатu Ontology Model by [18]. Therefore, knowledge management plays a big role in representing knowledge in software, documents and databases by the help of knowledge modelling which widely known as ontology model as according to [19], web ontology language (OWL) has become new standard for knowledge presentation.

\section{RESEARCH METHOD}

There are a lot of methods can be used to develop the ontology, but according to [20], it must meet the purpose and reasons why it is being designed. There are few stages need to be done before the validated ontology model of intake and preparation of MCD is published. In the planning stage, the domain of the 
ontology research area is determined. In this paper, we have decided to choose intake and preparation of MCD as the main domain. Next is data collection and analysis. Through the previous research, we have identified that most of the knowledge about MCD are tacit knowledge. Hence, a few Malay traditional midwives were interviewed in order to get some data regarding intake and preparation of food and its recipes in MCD. During the interview, the previous data of allowed foods were given to the midwives. From the data, the midwives explained on what kind of preparation methods as suggested by $[21,22]$ that might be suitable with Malay dishes. The example of data is shown in Table 1.

Table 1. The preparation method of allowed food in MCD

\begin{tabular}{ccccccccccc}
\hline Food & Freeze & Dry & Steaming & Microwaving & Boiling & Grilling & Frying & Drain & Reheat & Raw \\
\hline Beef & $\checkmark$ & & $\checkmark$ & $\checkmark$ & $\checkmark$ & $\checkmark$ & $\checkmark$ & $\checkmark$ & $\checkmark$ & \\
Mutton & $\checkmark$ & & $\checkmark$ & $\checkmark$ & $\checkmark$ & $\checkmark$ & $\checkmark$ & $\checkmark$ & $\checkmark$ & \\
Chicken & $\checkmark$ & $\checkmark$ & $\checkmark$ & $\checkmark$ & $\checkmark$ & $\checkmark$ & $\checkmark$ & $\checkmark$ & $\checkmark$ & \\
Anchovy & $\checkmark$ & $\checkmark$ & $\checkmark$ & $\checkmark$ & $\checkmark$ & $\checkmark$ & $\checkmark$ & $\checkmark$ & $\checkmark$ & \\
Mackerel & $\checkmark$ & $\checkmark$ & $\checkmark$ & $\checkmark$ & $\checkmark$ & $\checkmark$ & $\checkmark$ & $\checkmark$ & $\checkmark$ & \\
Jewfish & $\checkmark$ & $\checkmark$ & $\checkmark$ & $\checkmark$ & $\checkmark$ & $\checkmark$ & $\checkmark$ & $\checkmark$ & $\checkmark$ & \\
\hline
\end{tabular}

Next, the dish recipes were also analyze according to data from [6, 7] and [23]. The recipes were analyzed according to the combination of allowed food from the previous ontology and the midwives were agreed that the combination of the allowed foods were good for mother's health. Hence, after the data collection and analysis is done, next stage is to design the ontology. In designing the ontology, the steps inside Ontology Development 101 [24] as shown in Figure 1 is followed:

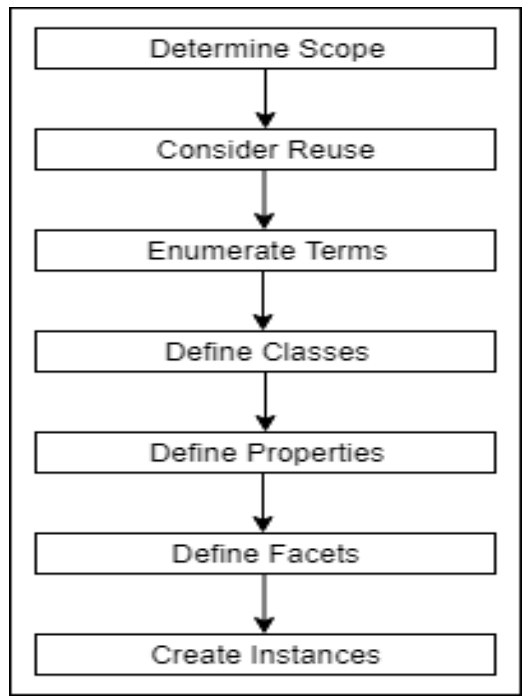

Figure 1. Ontology development 101 steps [22]

The step of creating an ontology model starts by defining the domain or scope of the ontology model which is the MCD. Then the choice of reusing existing ontology model which is MCD and Phytochemical ontology model is decided. Then the related terms of the intake and preparation of MCD is listed down. The terms are divided into types and subtypes where the type method of preparation has subtypes like steam, grill and boil. The type and subtypes are defined based on the top-down development process where the type is defined first then the subtypes which is then organized into a hierarchical taxonomy. Furthermore, more details on the classes are defined such as the properties of the class which is then became the slots of the class. The slots of each classes must be described with the value type, allowed values, cardinality and other features. For example, slot-value type for nutrient deficiency is number. Lastly, the individual instances of a class are defined. Once the ontology model is constructed, then, the testing is conducted using SPARQL query, whether it will generate expected information or not. If everything is fine, ontology model for intake suggestion and preparation for Malay confinement dietary recipes is then validated. 


\section{RESULTS AND ANALYSIS}

Based on the steps in Ontology Development 101, the classes should be defined first after the domain (MCD) and terms (intake suggestion and preparation method with recipes) is defined. This section is divided into 4.1 classes and object properties creation and 4.2 relationship between the classes and object properties and 4.3 testing of the ontology.

\subsection{Classes and Object Properties Creation}

Originally, from the ontology model, a few classes were existed. In this research, three new classes have been added which are Intake, Preparation and Purpose as shown in Figure 2.

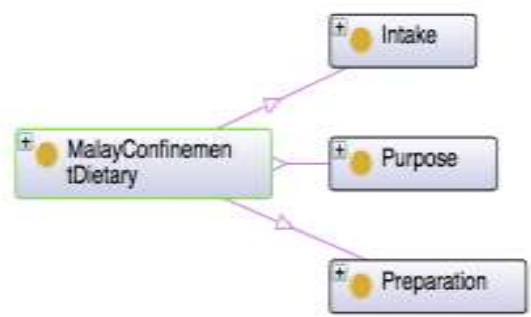

Figure 2. New classes inside the original MCD Ontology Model

For each new class, some subclasses have been added according to its own taxonomy. For example, the Intake class consists of three subclasses which are the Breakfast, Lunch and Dinner. This data was taken from the article that talks about the conventional meal pattern for a person that were written by [25]. Besides that, the Purpose class is created and can be divided into Dish, Reheat_Food and Storage. The class Storage were retrieved from the web page that explains on the preparation of food $[16,17]$. The Dish class contains several instances which the recipes, are taken from three recipe books which were written by [6, 7] and [18]. Hence, from the classes itself, we can see the visualization of the data in the ontology. For example, the food can be taken according to subclasses inside Intake class. The food also will have different purpose that can be visualized. For example, it can be used for dish. And the food also has some preparation method according to dish and its recipes. The example of ontograph for Purpose class is show in Figure 3.

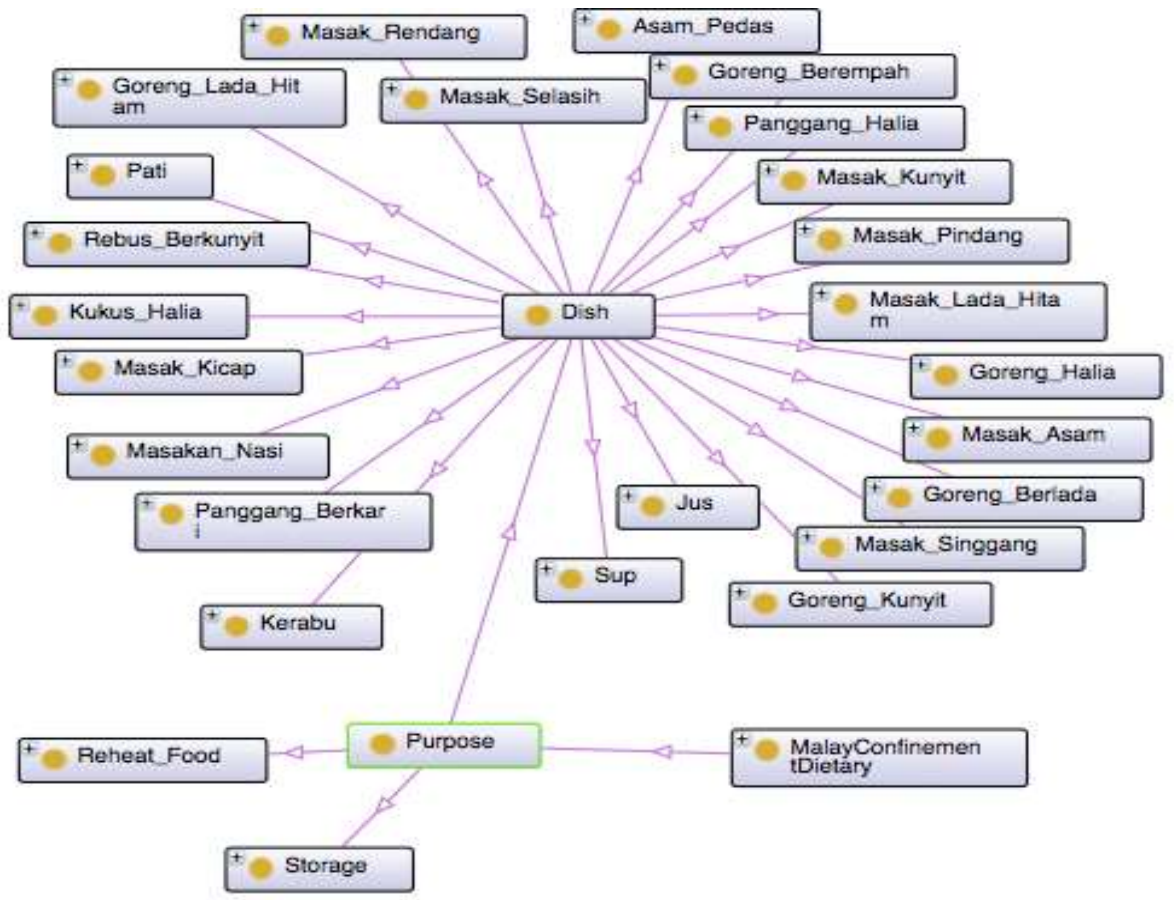

Figure 3. Ontograph of Purpose class in MCD Ontology Model 
Next, Preparation class contains six subclasses which are Cook_and_Drain,Dry, Reheat, Raw, Cook and Freeze. Meanwhile, Cook has further instances which are Steaming, Grilling, Frying, Boiling and Microwaving. These data were retrieved from a web page that talks about the nutrient loss in each of the preparation method of food [20]. Once all the classes are created, these classes are connected using object properties based on their relationships with each class. The ontology model of intake and preparation of MCD consists of four (4) object properties which are; hasIntakeTime, hasPurpose, hasPreparationMethod and hasIngredients.

Meanwhile the restriction for each of the object properties is some. The word 'some' in the context of ontology development represents the multiple relationship between the classes. This means that a class may have one or more relationship with another class. 'Some' is used for each of the object properties as each classes have one more relationship with another classes.

Based on Figure 4, this object property of hasIntakeTime has Dish, Food and Herbs as its domain and Intake as its range. By applying the restriction of 'some' to this object property, it explains that Dish, Food and Herbs may have one or more Intake.

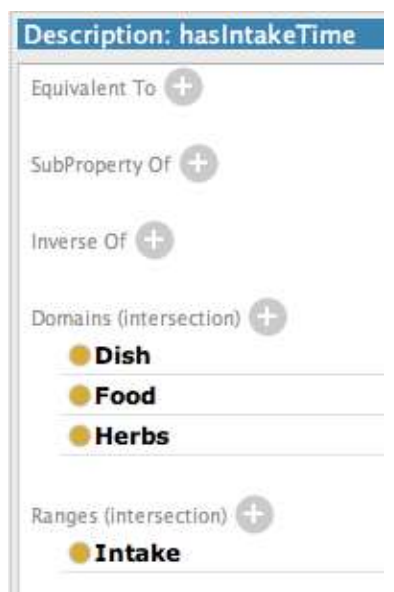

Figure 4. hasIntakeTime object property in MCD Ontology Model

\subsection{Classes and Object Properties Relationship}

Technically, all the new classes and object properties must be connected to each other to have a connection which we called as ontology. For example, a dish type can be taken during what time of the suggested 3 meals a day as in Figure 5.

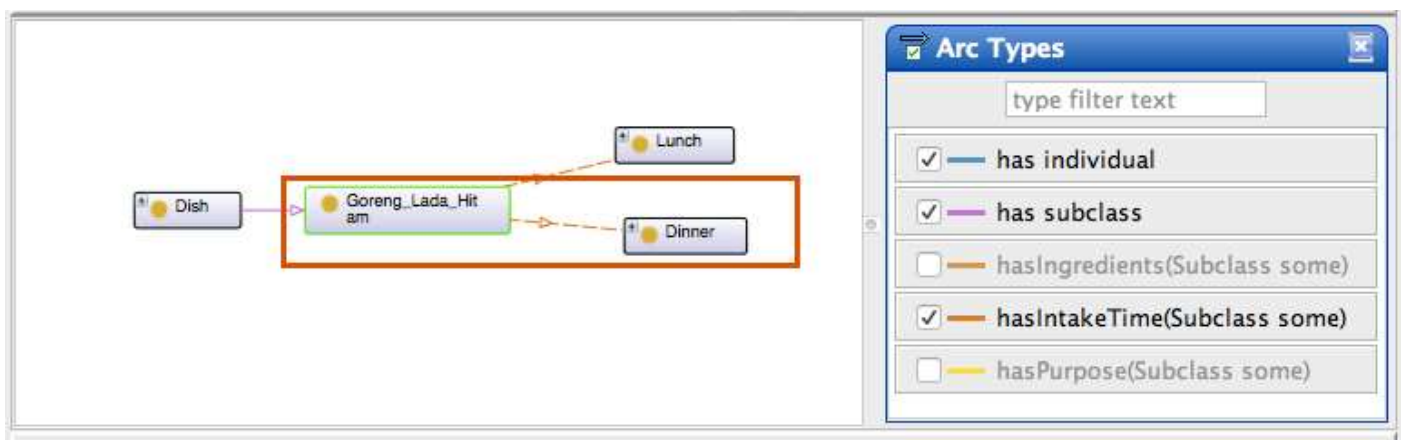

Figure 5. Dish and Intake classes are connected through object properties

From the example, the relationship between a dish and an intake time which explains that the dish Goreng Lada Hitam is the domain has dinner or lunch as its intake time (range). Same method applies to the other four object properties as shown below in Figure 6. 


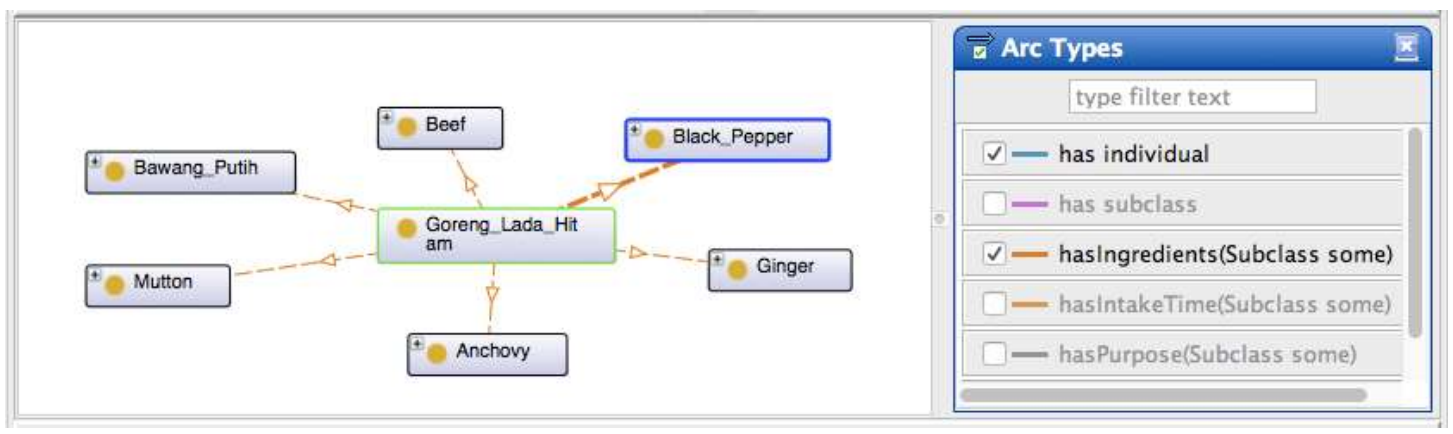

Figure 6. Goreng Lada Hitam dish has combination of allowed food in MCD

In order to make a Goreng Lada Hitam dish, the allowed foods from MCD ontology model is used, which shows and integrated model with the new classes added. For overall ontology model of the new classes, the type of food that will be used as an example for the representation of the Intake Suggestion and Preparation of MCD Recipes ontology model is Beef. The example below shows the relationship of Beef which an allowed food for mothers to consume with other allowed foods and herbs.

Figure 7 shows the Beef relationship with the three new classes added. In the Arc Types, it shows the colour for each object properties to make user easier to see different kind of relationships. From the ontology model itself, we can see that Beef hasPreparationMethod of Frying which has a recipe of that relates to hasPurpose object property that includes Goreng Lada Hitam recipe. This recipe hasIngredients which includes Black Pepper and Ginger which are also the allowed foods in MCD. This Goreng Lada Hitam Beef hasIntakeTime at Dinner or Lunch depends on the mothers' preference. Hence, from the allowed food of previous MCD ontology model, it can be integrated to get what is the suggested intake time together with the preparation methods and recipe for mothers in confinement.

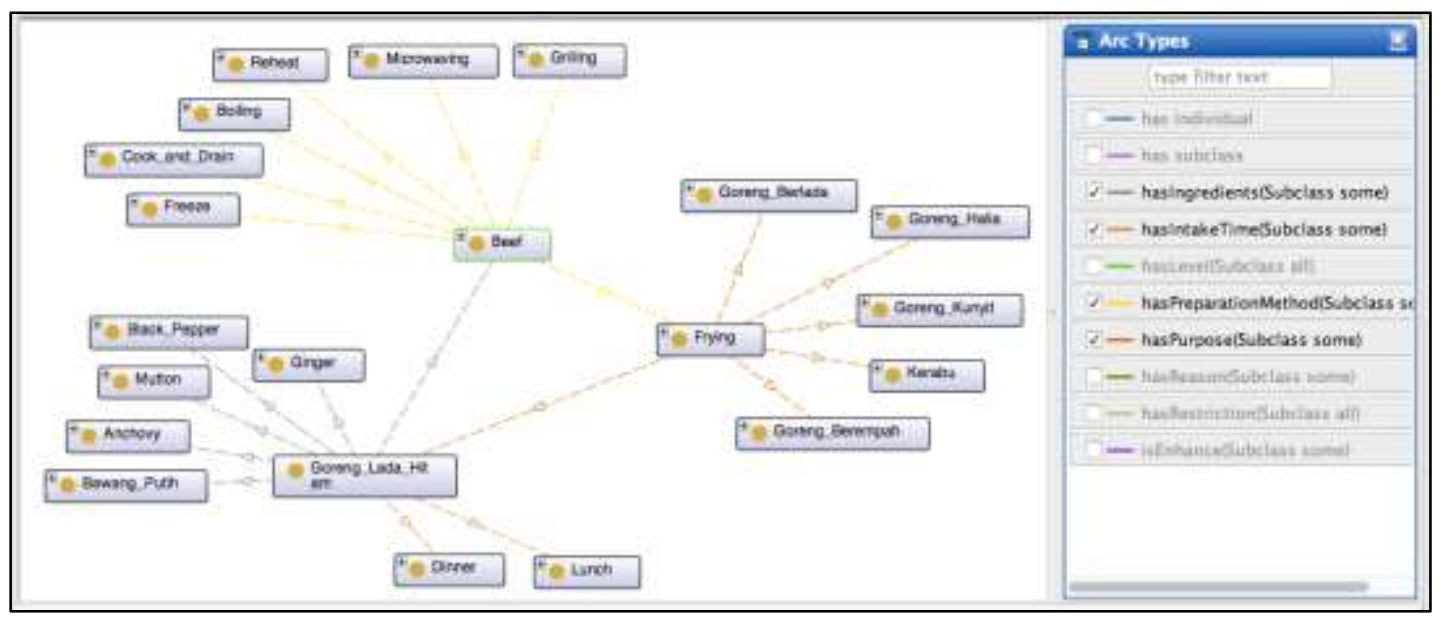

Figure 7. Overall ontology framework for Beef

\subsection{Testing of the Ontology}

To test whether the ontology can retrieve the correct information or not according to what we have been visualized, SPARQL query is used to be executed inside the ontology model. From Figure 8 , the SPARQL query that is executed is to find, if Goreng Lada Hitam dish is about to be prepared, what are the allowed foods inside MCD ontology model that can be used as its ingredients which has been identified through hasIngredients object property. Based on the result, it gave the correct information as what is needed if the dish is about to be prepared. Hence, we can verify here that all the new classes and object properties that were added has its own purpose that can give more value to the current MCD ontology model. 


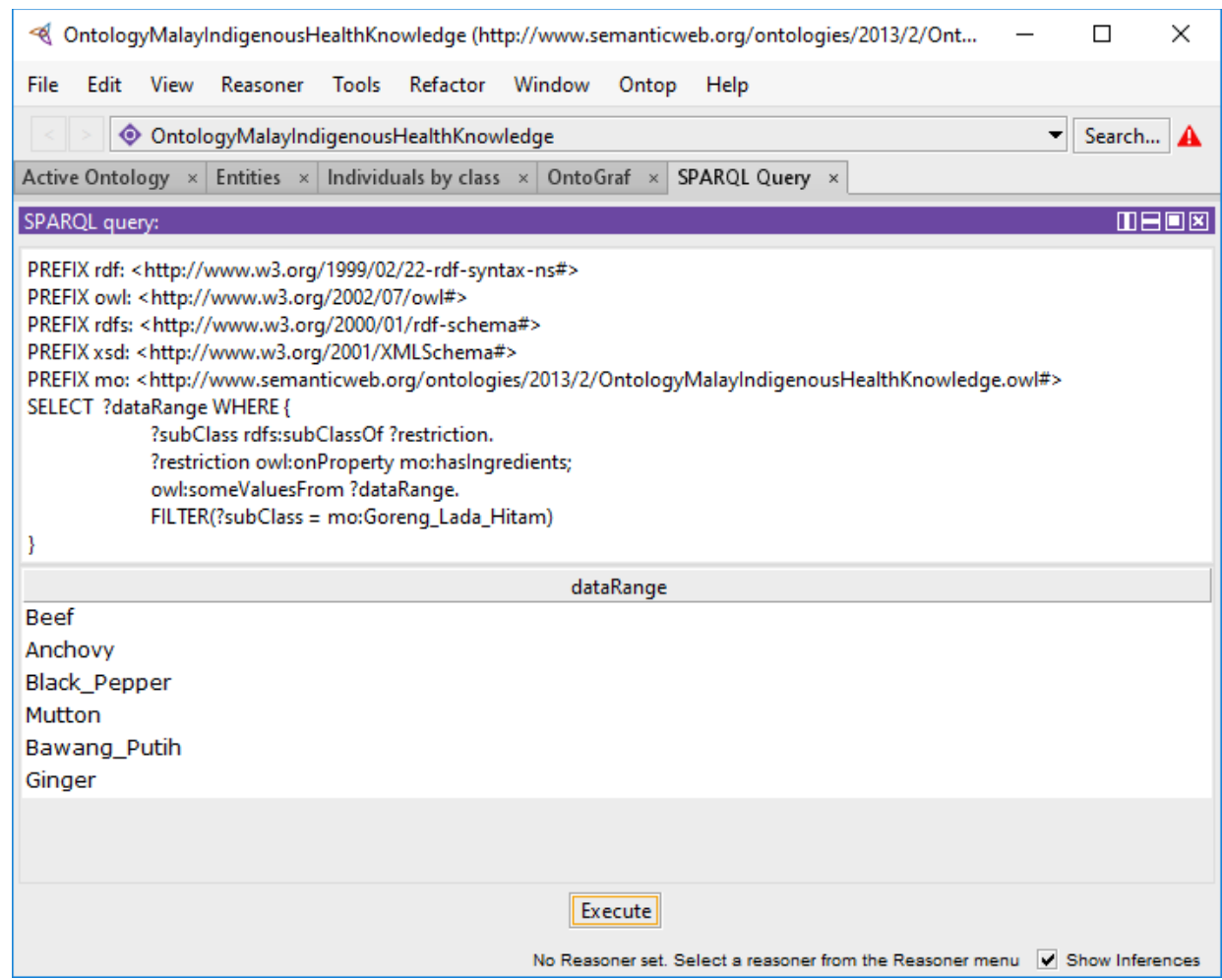

Figure 8. SPARQL query of Goreng Lada Hitam which use the hasIngredients object property

\section{CONCLUSION}

This paper presents the ontology model MCD recipes which include the intake suggestion and its preparation. MCD is a tradition which is still being experienced up until now by Malay society in Malaysia. Normally, most of the knowledge regarding MCD are tacit and only known by expertise only. Previously, some works had been done in order to model the tacit knowledge which is resulted to construction of MCD ontology model. In the current model, it tackles what are the allowed and non-allowed foods, what kind of nutrients those food can enhance in the mothers' body and its phytochemical benefits in allowed fruits and vegetables. Currently, the model does not cover on the intake suggestion and what kind of preparation methods can be done to the food so that it will become a tasty dish to mothers in confinement to consume. The intake of MCD covers the correct time for mothers in confinement to consume their food while the preparation of MCD covers the correct way to prepare the dish of confinement food. Nevertheless, these intake and preparation knowledge will lead to extinction if it is not being preserved as the knowledge can only be fetched from the tacit knowledge of Malay traditional midwives. This is where the use of knowledge modelling, to be exact, a representation of ontology model is being used. An ontology model can help prevent the extinction of knowledge of the intake and preparation of MCD as the knowledge is collected, organized and authorized.

Before constructing the ontology model, the data collection and analysis is done to get the valuable knowledge from the midwives. Then, the ontology model was designed with the guidelines of Ontology Development 101. The MCD ontology model were reuse with the addition of three new classes which are Intake, Purpose and Preparation. Each class has its own subclasses which leads to hierarchical taxonomy. Besides that, four different object properties such as hasIntakeTime, hasPurpose, hasPreparationMethod and hasIngredients were added to give associations between old classes and new classes that were added in the current ontology model. In the end, SPARQL query is used to test whether the extended new ontology model could retrieve the correct information or not. Based on our new added data, the correct information is retrieved once the query is executed. Hence, we can conclude that all the new classes and object properties that were added could give significant value to the current MCD ontology model.

For future work, the preparation of the dish should be explained more especially the exact amount of nutrient in the dish and how much nutrient will lost if the food is prepared in different preparation methods. In conclusion, this ontology model can be used to preserve the tacit knowledge especially. It might be valuable and useful for the future generations to learn on the previous generation's practice regarding MCD if the model is keep updated. 


\section{ACKNOWLEDGEMENTS} financially.

The authors are thankful for the support given by Universiti Teknologi MARA for this work

\section{REFERENCES}

[1] Fok, D., Aris, I. M., Ho, J., Lim, S. B., Chua, M. C., Pang, W. W. "A comparison of practices during the confinement period among Chinese, Malay, and Indian mothers in Singapore." Birth, 43(3), 247-254, 2016

[2] Serbesa ML, Iffa MT. "Knowledge, attitude and practice on prevention of iron deficiency anemia among pregnant women attending ante-natal care unit at public hospitals of Harar Town, Eastern Ethiopia: institutional based crosssectional study." Int J Pregn \& Chi Birth. 2019;5(2):48-55. DOI: 10.15406/ipcb.2019.05.00146

[3] Haron, Haryani \& Hamiz, M.. "An Ontological Framework to Preserve Malay Indigenous Health Knowledge." Advanced Science Letters. 20. 226-230, 2014.

[4] M Hamiz, Haryani Haron, Azlin Sanusi, M Bakri, Nur Syamira Mohd Nazaruddin. "Semantic Web Representation for Phytochemical Ontology Model”. Journal of Telecommunication, Electronic and Computer Engineering (JTEC). 10 1-5. 183-186. 2018.

[5] Liyana Lazim, Nur \& Hamiz, M \& Haron, Haryani \& Bakri, Mohammad. "Intake and Preparation of Malay Confinement Dietary Ontology Framework”. International Visual Informatics Conference 62-70. 2017

[6] Din, C. N. A. N. Kompilasi Hidangan Berpantang: Alaf 21. Retrieved from https://books.google.com.my/books?id=U7WcDQAAQBAJ, 2010

[7] Arukin, S. M. Menu Ibu \& Anak (Hidangan Ibu Berpantang \& Selera Si Manja): Alaf 21 @ Grup Buku Karangkraf. Retrieved from https://books.google.com.my/books?id=ORNIDQAAQBAJ. 2016.

[8] Fadzil, F., Shamsuddin, K., Ezat, S., \& Puteh, W. "Traditional Postpartum Practices Among Malaysian Mothers" J Altern Complement Med. 2016 Jul;22(7):503-8

[9] Manal Abdullah, Monirah Almalki, Hanaa Blahmer. "E - Collaboration Knowledge Management". International Journal of Advanced Trends in Computer Science and Engineering,Volume 8, No.1.1, 2019

[10] Koenig, M. E. D. What is KM? Knowledge Management Explained. Retrieved from http://www.kmworld.com/Articles/Editorial/What-Is-.../What-is-KMKnowledge-Management-Explained82405.aspx. 2012.

[11] Sabri S.M., Haron H., Jamil N. (2017) "A Design of a Reminiscence System for Tacit Knowledge Recall and Transfer.” In: Mohamed A., Berry M., Yap B. (eds) Soft Computing in Data Science. SCDS 2017. Communications in Computer and Information Science, vol 788. Springer, Singapore.

[12] Corcho, Oscar \& Fernández-López, Mariano \& Gomez-Perez, Asuncion. (2007). "Ontological Engineering: What are Ontologies and How Can We Build Them?”. Semantic Web Services: Theory, Tools and Applications. 10.4018/978-1-59904-045-5.ch003.

[13] Gruber, T. R., \& others. "A translation approach to portable ontology specifications". Knowledge Acquisition, 5(2), 199-220. 1993

[14] Studer, R., Benjamins, V. R., \& Fensel, D. "Knowledge engineering: principles and methods". Data \& Knowledge Engineering, 25(1-2), 161-197. 1998

[15] Chandrasekaran, B., Josephson, J. R., \& Benjamins, V. R. "What are ontologies, and why do we need them?" IEEE Intelligent Systems and Their Applications, 14(1), 20-26. 1999.

[16] Syerina Azlin Md Nasir, Nor Laila Md Noor, "A Practical Approach for Ontology Construction through Mapping Process", Knowledge Management International Conference (KMICe2014), 279-284, 2014.

[17] Lord, P. Components of an Ontology. Ontogenesis. Retrieved from http://ontogenesis.knowledgeblog.org/514. 2010.

[18] Gunawan, Ridowati \& Mustofa, Khabib. "Finding Knowledge from Indonesian Traditional Medicine using Semantic Web Rule Language". International Journal of Electrical and Computer Engineering (IJECE). 7. 36743682. 2017.

[19] Suwan Tongphu, Boontawee Suntisrivaraporn, Pakinee Aimmanee, "Toward Semantic Similarity Measure Between Concepts in an Ontology," Indonesian Journal of Electrical Engineering and Computer Science (IJEECS). Vol. 14, No. 3, 2019

[20] Shaharudin, Ahmad \& Abdul Latiff, Ahmad \& Haron, Haryani \& Annamalai, "Muthukkaruppan. Software Engineering Approach For Domain Ontology Development: A Case Study Of Islamic Banking Product." Journal of Information Retrieval and Knowledge Management. 3. 36-53. 2017.

[21] Storage. Retrieved October 17, 2017, from https://www.britannica.com/technology/storage-goods. 1998

[22] Yuan, G., Sun, B., Yuan, J., \& Wang, Q. "Effects of different cooking methods on health-promoting compounds of broccoli", Journal of Zhejiang University SCIENCE B 10(8):580-8 · September 2009.

[23] Fazalina, C. Resipi Kontemporari : Ibu Berpantang: PTS Millennia. Retrieved from https://books.google.com.my/books?id=bU6MBQAAQBAJ, 2014.

[24] Noy, N. F., \& McGuinness, D. L. "Ontology Development 101: A Guide to Creating Your First Ontology". Stanford Knowledge Systems Laboratory, 25. 2001.

[25] Roos, E., \& Prättälä, R. "Meal Pattern and Nutrient Intake among Adult Finns.” Appetite, 29(1), 11-24. 1997 